\title{
Research on myoma in Northeastern Romania and socio-medical outcomes
}

\author{
DANIELA ROXANA MATASARIU ${ }^{1}$, ALEXANDRA URSACHE ${ }^{1}$, LOREDANA HIMINIUC $^{1}$, BOGDAN TOMA $^{1}$, \\ VASILE LUCIAN BOICULESE ${ }^{2}$, MIHAELA GRIGORE ${ }^{1,3}$ and IRINA DUMITRASCU ${ }^{1,3}$

\begin{abstract}
Departments of ${ }^{1}$ Obstetrics and Gynecology, and ${ }^{2}$ Preventive Medicine and Interdisciplinarity Medical Informatics and Biostatistics, 'Grigore T. Popa' University of Medicine and Pharmacy, 700115 Iasi; ${ }^{3}$ Department of Obstetrics and Gynecology, 'Cuza Voda’ Obstetrics and Gynecology Clinical Hospital, 700038 Iasi, Romania
\end{abstract}

Received August 6, 2021; Accepted September 7, 2021

DOI: $10.3892 /$ etm.2021.10952

\begin{abstract}
Myomas are the most common benign uterine tumors in women of childbearing age, with an incidence of up to $77 \%$ and a major impact on women's health. The aim of our study was to provide information concerning the incidence and prevalence of myomas in the patients admitted to a tertiary referral center in Northeastern Romania. This retrospective study conducted at the Iasi 'Cuza Voda' University Hospital of Obstetrics and Gynecology (Romania) included 11,538 patients, representing all patients admitted to the gynecology department between January 2013 and December 2019. During the study interval, the number of hysterectomies (total and for myomas) had increased. The rate of laparoscopic surgery showed a small decrease (31.3\% from 34\%), classic therapy showed a decrease by more than $10 \%$ and the hysteroscopy rate was tripled. There are few studies in the literature that have established with accuracy the incidence of myomas. In the present study, the prevalence of hysterectomy for myomas was $54.42 \%$. Our results are in agreement with the data in the literature, namely that $40-60 \%$ of all performed hysterectomies are for myomas. The vast majority of admissions for myomas involve a surgical procedure most commonly hysterectomy.
\end{abstract}

\section{Introduction}

Myomas or fibroids are a type of benign uterine smooth muscle tumors, found in women of reproductive age, with an incidence of up to $70 \%$ (1-4). Myomas are frequently diagnosed in $20-25 \%$ of women of reproductive age (30-40 years) and $30-40 \%$ of women older than 40 years (5-9). They often

Correspondence to: $\mathrm{Dr}$ Alexandra Ursache, Department of Obstetrics and Gynecology, 'Grigore T. Popa' University of Medicine and Pharmacy, 16th University Street, 700115 Iasi, Romania

E-mail: carpalecsandra@yahoo.com

Key words: myoma, hysterectomy, myomectomy, quality of life, women's health, racial differences have a negative impact on reproduction. They can be single, but more often multiple, causing significant morbidity and deterioration of quality of life $(5,9,10)$. Most women are asymptomatic, only $30-40 \%$ of them present with symptoms such as heavy menstrual bleeding, lower abdominal pain, infertility, recurrent pregnancy loss, dyspareunia, abdominal bloating or constipation, increased urinary frequency or incontinence, anemia from heavy bleeding, fatigue, and pressure symptoms. The severity of symptoms depends on the size, location, and number of myomas (11-14). Based on the relationship between the myoma and the uterine wall, there are three types of myomas: submucous myoma, intramural myoma, and subserous myoma (15).

For most of the women presenting with myomas, the treatment remains, in the end, surgical removal $(1,2)$. Myomectomy is the gold standard treatment in women who wish to preserve their fertility. It can also be performed in those women who desire to preserve the uterus for social, cultural, and psychological reasons, even if they have a complete family (16).

The techniques used in gynecological practice include abdominal myomectomy, transvaginal myomectomy, laparoscopic myomectomy, laparoscopically assisted myomectomy via minilaparotomy incision, and robot-assisted laparoscopic myomectomy (1,6-8). Additional interventions to reduce intraoperative bleeding during myomectomy are uterine artery embolization/ligation, pericervical tourniquet placement, intramyometrial vasopressin/epinephrine administration, use of uterotonics (e.g. ergometrine, oxytocin and misoprostol), and antifibrinolytic agents (e.g. tranexamic acid, recombinant factor VIIa) $(2,17)$.

The data regarding the associated epidemiological factors are either well-defined or not yet completely understood. These factors are age, race, heritage, sex hormone imbalance, earlier age at menarche, obesity, lifestyle factors (diet, caffeine, alcohol, smoking, and stress), environmental factors, and possibly many others. In the literature, the impact of these factors remains conflicting. It may be attributed to selection bias, given the fact that studies are based on surgical/symptomatic cases, or on the incidental diagnosis of myomas $(5,9,18-20)$.

The data on racial differences, other than in Caucasian and African American women, are limited $(9,18,21)$. 
Though most women are asymptomatic, myoma symptoms can affect the quality of a woman's life.

The incidence and prevalence of myomas remain currently unknown (22-25). Stating the fact that the incidence of myoma varies greatly around the world, the aim of our study was to provide information about the incidence and prevalence of this disease in the gynecological patients admitted to the Iasi 'Cuza Voda' University Hospital of Obstetrics and Gynecology in Northeastern Romania.

\section{Patients and methods}

This retrospective study conducted at the Iasi 'Cuza Voda' University Hospital of Obstetrics and Gynecology (Romania) included 11,538 patients, representing all patients admitted to the Gynecology Department between January 2013 and December 2019. All these patients had surgical interventions performed in our hospital from which 4,035 were hysterectomies. From all the 4,035 hysterectomies performed, only 2,196 were performed for myomas.

The present study aimed at establishing the detection rate of myoma cases, as well as the differential diagnosis with other pelvic diseases.

During the study interval, patients with different gynecological conditions were admitted for surgical reasons (laparoscopy, open laparotomy, hysteroscopy). The obstetric patients were excluded from the study. Of the 11,538 patients only 2,786 met the inclusion criteria. They had a surgery prior diagnosis of myoma, histopathologically confirmed afterwards. From these 2,786 patients with myomas, 590 had myomectomy performed and 2,196 had hysterectomy performed for this diagnosis.

All patients signed our hospital informed consent. Institutional review board approval from the Ethics Committee of 'Cuza Voda' Iasi University Hospital of Obstetrics and Gynecology was obtained to conduct this retrospective study (10425/2021).

Statistical analysis. The emphasis of this study is on proportion estimates. Therefore, the absolute and relative frequencies were computed. For a consistent information estimation, we used the confidence interval with standard 0.95 probability (95\% CI). The binomial proportion confidence interval using the Clopper-Pearson (exact method) formula was applied in order to have a minimum coverage probability of 0.95 (conservative method). Computations were made in $\mathrm{R}$ version 4.0.2 (2020-06-22) using the package DescTools (version 0.99.40, https://www.rdocumentation. org/packages/DescTools/versions/0.99.40) (26).

\section{Results}

Of the total number of 11,538 surgeries performed in our gynecology department during 2013-2019, 4,035 were hysterectomies, meaning that approximatively one-third of the total surgeries (34.97\%) (95\% CI: 34.10-35.84) were hysterectomies.

Table I shows the total number of hysterectomies and hysterectomies for myomas, and their corresponding percentage and confidence interval. During the study interval, the number of hysterectomies (total and for myomas) increased from 2013 to 2017.

From 2013 to 2017 there was also an increase in the percentage of hysterectomies from 22.64 to $73.31 \%$, followed by a decrease to $64.45 \%$ in 2018 , and to $68.57 \%$ in 2019 , which means that two-thirds of the hysterectomies were performed for myomas. The percentage for the entire period 2013-2019 was $54.42 \%$. As a general rule, confidence intervals are wider for small sample sizes.

In Table II, the total gynecological surgical cases, myoma cases and the percentage of myomas (with 95\% CI) from total surgical cases from 2013-2019 are documented. All of these values increased with time, the only exception being the year 2015 .

The percentage of myomas from the total surgeries performed, during the study period, almost doubled from $3.40 \%$ (2.52-4.46) in 2013 to $6.43 \%$ (5.34-7.67) in 2019.

Table III shows, along with the $95 \%$ CI, the percentage of each type of surgery for myoma. Studying the values, no general rules, such as increasing or decreasing trend with time are noted. Consequently, we compared the 2019 percentages with the 2013 baseline. The rate of laparoscopic surgery showed a small decrease [34\% (2013) to $31.30 \%$ (2019)], classic therapy showed a decrease by more than $10 \%$ [from $54 \%$ (2013) to $29.56 \%$ 2019)] and the rate of hysteroscopy rate tripled (12\% (2013) to 39.14\% (2019)] in 2019 compared to 2013.

Table IV shows that the rate of intramural and subserous myomas had a positive trend from $23.07 \%$ in 2013 to 54.29 in 2019 , while for the submucous type, the trend was descending from $76.92 \%$ in 2013 to 45.69 in 2019. The same positive correlation was observed in uterine myoma cases during this period. The number of uterine myoma cases grew from $5.6 \%$ cases in 2013 to $20.03 \%$ cases in 2019 . Finally, the percentage of surgical methods used are presented in Fig. 1.

\section{Discussion}

Uterine myomas are the most common indication for hysterectomy worldwide $(9,27,28)$. Ultrasound studies have shown that the prevalence of myoma is much lower in Europe than in the United States, possibly due to racial differences. The prevalence of myoma was highly underestimated in previous epidemiological studies, that only focused on symptomatic patients. Epidemiological studies have become more accurate using more advanced imaging techniques (3D-4D ultrasonography) $(5,7,9,18,19,29,30)$. In our study, the prevalence of hysterectomy for myomas was $54.42 \%$. Our results are in agreement with the data in the literature, namely that $40-60 \%$ of all performed hysterectomies are for myomas. The vast majority of admissions for myomas involve a surgical procedure (94.4\%), most commonly hysterectomy $(79.2 \%)(14,31)$.

As in our hospital all patients were Caucasian, we were unable to determine a race-specific prevalence. Laughlin et al (23) determined the following prevalence for myomas by race: $18 \%$ in Black women, $8 \%$ in Caucasian women, $10 \%$ in Hispanic women, and $13 \%$ in an 'Others' group, consisting largely of Asian women (23). In regards to Caucausian women, contrary to the above-mentioned study, in our study the prevalence was higher. 
Table I. Number and percentage of hysterectomies in the period 2013-2019.

\begin{tabular}{lcrr}
\hline Year & Total hysterectomies n $(\%$ of the total) & Hysterectomies for myomas n $(\%$ of the total) & Percentage $\%(95 \%$ CI $)$ \\
\hline 2013 & $468(11.59)$ & $106(4.82)$ & $22.64(18.93-26.71)$ \\
2014 & $527(13.07)$ & $200(9.11)$ & $37.95(33.79-42.24)$ \\
2015 & $535(13.25)$ & $229(10.43)$ & $42.80(38.56-47.12)$ \\
2016 & $543(13.46)$ & $312(14.20)$ & $57.45(53.17-61.65)$ \\
2017 & $652(16.15)$ & $478(21.78)$ & $73.31(69.74-76.67)$ \\
2018 & $664(16.46)$ & $428(19.49)$ & $64.45(60.68-68.1)$ \\
2019 & $646(16.01)$ & $443(21.17)$ & $68.57(64.83-72.14)$ \\
Total & $4,035(100)$ & $2,196(100)$ & $54.42(52.87-55.96)$ \\
\hline
\end{tabular}

Table II. Number and percentage of myomas from the total gynecological surgeries.

\begin{tabular}{lccc}
\hline Year & Total surgeries n $(\%$ of the total) & Myomas n $(\%$ of the total) & Percentage of myomas from surgeries (95\% CI) \\
\hline 2013 & $1,468(12.72)$ & $50(8.47)$ & $3.40(2.53-4.46)$ \\
2014 & $1,610(13.95)$ & $81(13.72)$ & $5.03(4.01-6.21)$ \\
2015 & $1,531(13.26)$ & $58(9.83)$ & $3.78(2.88-4.87)$ \\
2016 & $1,675(14.51)$ & $74(12.54)$ & $4.41(3.48-5.51)$ \\
2017 & $1,741(15.08)$ & $104(17.62)$ & $5.97(4.90-7.19)$ \\
2018 & $1,726(14.95)$ & $108(17.30)$ & $6.25(5.16-7.50)$ \\
2019 & $1,787(15.48)$ & $115(19.49)$ & $6.43(5.34-7.67)$ \\
Total & $11,538(100)$ & $590(100)$ & $5.11(4.71-5.53)$ \\
\hline
\end{tabular}

Table III. Types of surgery for myomas.

\begin{tabular}{lcccc}
\hline Year & $\begin{array}{c}\text { Myoma cases, } \mathrm{n} \\
(\% \text { of the total })\end{array}$ & $\begin{array}{c}\text { Laparoscopy cases, } \mathrm{n}(\%) \\
(95 \% \mathrm{CI})\end{array}$ & $\begin{array}{c}\text { Classic cases, } \mathrm{n}(\%) \\
(95 \% \mathrm{CI})\end{array}$ & $\begin{array}{c}\text { Hysteroscopy cases, } \mathrm{n}(\%) \\
(95 \% \mathrm{CI})\end{array}$ \\
\hline 2013 & $50(8.47)$ & $17(34.00)(21.20-48.76)$ & $27(54.00)(39.32-68.18)$ & $6(12.00)(4.53-24.31)$ \\
2014 & $81(13.73)$ & $31(38.27)(27.68-49.74)$ & $41(50.62)(39.27-61.91)$ & $9(11.11)(5.20-20.04)$ \\
2015 & $58(9.83)$ & $19(32.75)(21.00-46.34)$ & $28(48.28)(34.95-61.78)$ & $11(18.97)(9.86-31.40)$ \\
2016 & $74(12.54)$ & $18(24.32)(15.09-35.69)$ & $37(50.00)(38.14-61.85)$ & $19(25.68)(16.22-37.15)$ \\
2017 & $104(17.63)$ & $27(25.97)(17.85-35.48)$ & $43(41.34)(31.77-51.42)$ & $34(32.69)(23.81-42.58)$ \\
2018 & $108(18.31)$ & $40(37.04)(27.94-46.86)$ & $33(30.55)(22.05-40.15)$ & $35(32.41)(23.71-42.09)$ \\
2019 & $115(19.49)$ & $36(31.30)(22.98-40.61)$ & $34(29.56)(21.42-38.79)$ & $45(39.14)(30.16-48.67)$ \\
Total & $590(100 \%)$ & $188(31.87)(28.11-35.79)$ & $243(41.19)(37.18-45.27)$ & $159(26.94)(23.4-30.72)$ \\
\hline
\end{tabular}

Table IV. Distribution of the types of myomas.

\begin{tabular}{lcccc}
\hline Year & $\begin{array}{c}\text { Uterine myoma cases, } \mathrm{n} \\
(\% \text { from total })\end{array}$ & $\begin{array}{c}\text { Submucous cases, } \mathrm{n}(\%) \\
(95 \% \mathrm{CI})\end{array}$ & $\begin{array}{c}\text { Intramural cases, } \mathrm{n}(\%) \\
(95 \% \mathrm{CI})\end{array}$ & $\begin{array}{c}\text { Subserous cases, } \mathrm{n}(\%) \\
(95 \% \mathrm{CI})\end{array}$ \\
\hline 2013 & $156(5.60)$ & $120(76.92)(69.51-83.28)$ & $22(14.10)(9.05-20.56)$ & $14(08.97)(4.99-14.59)$ \\
2014 & $281(10.09)$ & $166(59.07)(53.07-64.87)$ & $67(23.84)(18.98-29.26)$ & $48(17.08)(12.87-22.00)$ \\
2015 & $287(10.30)$ & $191(66.55)(60.76-71.98)$ & $63(21.95)(17.29-27.19)$ & $33(11.49)(8.04-15.76)$ \\
2016 & $386(13.85)$ & $247(63.98)(58.97-68.78)$ & $99(25.64)(21.36-30.31)$ & $40(10.36)(7.50-13.84)$ \\
2017 & $582(20.89)$ & $341(58.59)(54.46-62.620)$ & $149(25.60)(22.10-29.35)$ & $92(15.80)(12.93-19.02)$ \\
2018 & $536(19.24)$ & $250(46.64)(42.35-50.96)$ & $190(35.44)(31.39-39.66)$ & $96(17.91)(14.75-21.42)$ \\
2019 & $558(20.03)$ & $255(45.69)(41.50-49.93)$ & $203(36.37)(32.37-40.52)$ & $100(17.92)(14.82-21.36)$ \\
Total & $2,786(100)$ & $1,570(56.35)(54.48-58.20)$ & $793(28.46)(26.79-30.17)$ & $423(15.18)(13.86-16.57)$ \\
\hline
\end{tabular}




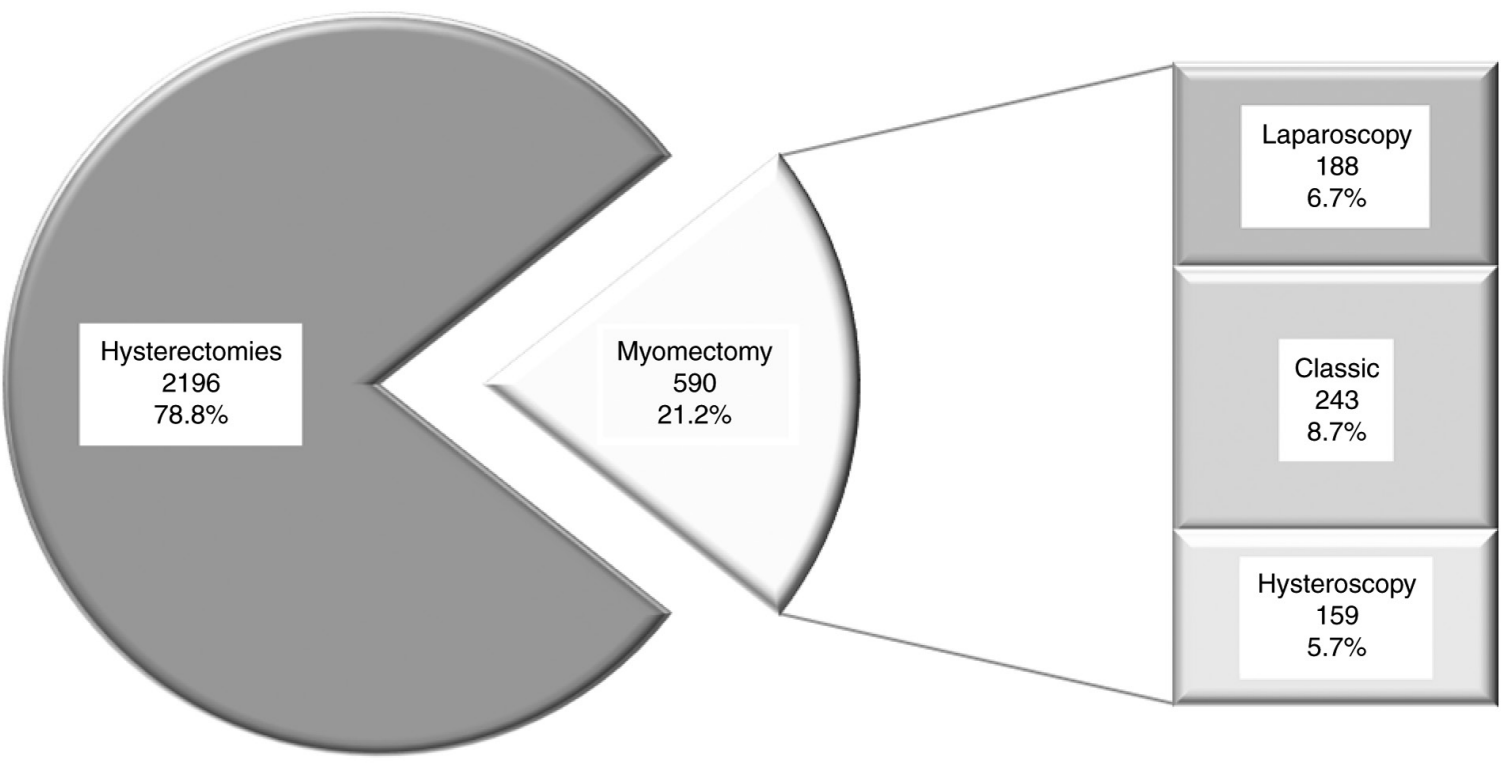

Figure 1. Surgical methods used for uterine fibroids.

Available data from different studies are difficult to compare because of the differences in the study population and screening methods (22-25). Findings from our study are based on a small sample size, thus the results should be considered with caution.

Different types of myoma have different impacts on fertility. The submucosal type lowers the fertility rate, intramural myomas may impair fertility, and the subserous type often has no impact on the fertility rate $(32,33)$.

The incidence of submucous myoma subtype is particularly high. These findings are in agreement with our results $(18,25)$. In our study the prevalence of submucous myoma from $2013-2019$ was $56.35 \%$; $28.46 \%$ for intramural myoma and $15.18 \%$ for subserous myoma.

Hysteroscopic transcervical resection of myomas also has some limitations, namely the potential conversion to laparotomy and incomplete resection. Many studies have compared the clinical outcomes of abdominal hysterectomy and laparoscopic or hysteroscopic surgery without reaching any conclusions concerning outcomes, advantages, and disadvantages of laparoscopic and hysteroscopic surgery (15,34-36). In our study 2,196 patients underwent hysterectomy for myoma and 590 myomectomy (243 patients with open myomectomy, 188 patients with laparoscopic myomectomy, and 159 patients hysteroscopic myomectomy).

It is quite difficult to assess accurately the incidence and prevalence of uterine myoma as these increase with aging. Myomas can seriously impact the lives of women and also are a significant healthcare burden. It has been estimated that the costs for uterine myomectomy/hysterectomy, in terms of care, adverse obstetric outcomes, and workhours lost, are higher compared to other benign gynecologic diseases (37). In the last decade, several conservative treatments have been developed for the management of uterine myomas (27,37-39).

The symptoms caused by myomas can affect the quality of life and sexual function of the patients. Despite the recent pharmacological and radiological interventions, surgery remains one of the main treatment options for symptomatic myomas in women of reproductive age. Postoperative quality of life and sexual function can be used to assess surgical outcomes in association with complication rates, blood loss, and duration of surgery (40-45).

Few studies have evaluated the patient-reported outcomes after surgical treatment. Radosa et al conducted a systematic literature search of PubMed. He found 29 articles but none of them had assessed the postoperative quality of life and sexual function in patients undergoing surgical treatment for myoma (45).

Uterine myomas remain the most common diagnosis among women admitted to our hospital. It is very important for the practitioner to understand the physical and psychological needs of these patients. Because many patients consider the uterus as a sexual organ, as a symbol of one's fertility, the surgeon must fathom its importance. This is the main reason why after hysterectomy most patients suffer an emotional trauma with a decrease in self-esteem, anxiety, and depression.

The lack of appropriate education and misconception in which concerns the uterus as a sexual organ might complicate or even worsen a preexisting psychiatric condition with major impact on sexual life.

The association between myomas and infertility may determine an increased level of stress in a couple, with a major impact on social life and relationship with the partner.

In conclusion, despite the substantial impact on gynecologic morbidity, relatively little is known about the etiology of myomas. Given the high frequency of asymptomatic myomas, the most accurate estimation of their prevalence and incidence comes from epidemiologic studies using ultrasound evaluation. A clear insight into the epidemiology of myomas is still not yet complete. Future research on the risk factors may help with prevention and may provide new conservative techniques. Considering their significant morbidity and impact on quality of life, more research focused on determining the risk factors associated with myoma onset and growth is needed. 
Our hospital is a tertiary referral center and thus the study was affected by the implicit statistical bias. Thus, an overestimation of hysterectomy for uterine myomas might occur because many of the cases treated in our department required difficult and complex surgical interventions, often these cases being referred to us from other gynecology services.

One major limitation of this study is that we did not apply a questionnaire for a better exposure of symptoms. A prospective study is needed to validate the impact of myomas on the quality of life using a questionnaire to evaluate symptoms of depression, infertility-related stress, and social aspects in postoperative patients. We still miss the means to accurately estimate these aspects. The limitation of our study is the one that opens for us new perspectives for further research.

\section{Acknowledgements}

Not applicable.

\section{Funding}

No funding was received.

\section{Availability of data and materials}

The datasets used and/or analyzed during this study are available from the corresponding author on reasonable request.

\section{Authors' contributions}

DRM, AU, LH and ID were involved in the conception of the study, data interpretation and writing of the manuscript. BT and VLB contributed to data collection and performed the statistical analysis. DRM and MG revised the manuscript for important intellectual content in regards to the literature data. All authors read and approved the final version of the manuscript for publication.

\section{Ethics approval and consent to participate}

Ethical approval was obtained from the Ethics Committee of the 'Cuza Voda' Obstetrics and Gynecology Clinical Hospital, Iasi (10425/2021) and our hospital inform consent was obtained from all participants.

\section{Patient consent for publication}

Not applicable.

\section{Competing interests}

The authors declare that they have no competing interests.

\section{References}

1. Zhang R, Shi H, Ren F and Yuan Z: Assessment of carboprost tromethamine for reducing hemorrhage in laparoscopic intramural. Exp Ther Med 10: 1171-1174, 2015.

2. Kongnyuy EJ and Wiysonge CS: Interventions to reduce haemorrhage during myomectomy for fibroids. Cochrane Database Syst Rev 8: CD005355, 2014.
3. Srivastava S, Mahey R, Kachhawa G, Bhatla N, Upadhyay AD and Kriplani A: Comparison of intramyometrial vasopressin plus rectal misoprostol with intramyometrial vasopressin alone to decrease blood loss during laparoscopic myomectomy: Randomized clinical trial. Eur J Obstet Gynecol Reprod Biol 228: 279-283, 2018

4. Baird DD, Dunson DB, Hill MC, Cousins D and Schectman JM: High cumulative incidence of uterine leiomyoma in black and white women: Ultrasound evidence. Am J Obstet Gynecol 188: 100-107, 2013.

5. Sparic R: Uterine myomas in pregnancy, childbirth and the puerperium. Srp Arh Celok Lek 142: 118-124, 2014 (In Serbian).

6. Fleischer R, Weston GC, Vollenhoven BJ and Rogers PA: Pathophysiology of fibroid disease: Angiogenesis and regulation of smooth muscle proliferation. Best Pract Res Clin Obstet Gynaecol 22: 603-614, 2008.

7. Okolo S: Incidence, aetiology and epidemiology of uterine fibroids. Best Pract Res Clin Obstet Gynaecol 22: 571-588, 2008.

8. Duhan N: Current and emerging treatments of uterine myoma an update. Int J Womens Health 3: 231-241, 2011.

9. Sparic R, Mirkovic L, Malvasi A and Tinelli A: Epidemiology of uterine myomas: A review. Int J Fertil Steril 9: 424-435, 2016.

10. Downes E, Sikirica V, Gilabert-Estelles J, Bolge SC, Dodd SL, Maroulis C and Subramanian D: The burden of uterine fibroids in five European countries. Eur J Obstet Gynecol Reprod Bio 152: 96-102, 2010

11. Kjerulff KH, Langenberg P, Seidman JD, Stolley PD and Guzinski GM: Uterine leiomyomas: Racial differences in severity, symptoms, and age at diagnosis. J Reprod Med 41: 483-490, 1996.

12. Lippman SA, Warner M, Samuels S, Olive D, Vercellini P and Eskenazi B: Uterine fibroids and gynecologic pain symptoms in a population-based study. Fertil Steril 80: 1488-1494, 2003.

13. Seracchioli R, Rossi S, Govoni F, Rossi E, Venturoli S, Bulletti C and Flamigni C: Fertility and obstetric outcome after laparoscopic myomectomy of large myomata: A randomized comparison with abdominal myomectomy. Hum Reprod 15: 2663-2668, 2000.

14. Wise LA and Laughlin-Tommaso SK: Epidemiology of uterine fibroids-from menarche to menopause. Clin Obstet Gynecol 59: $2-24,2016$

15. Zhang RC, Wu W, Zou Q and Zhao H: Comparison of clinical outcomes and postoperative quality of life after surgical treatment of type II submucous myoma via laparoscopy or hysteroscopy. J Int Med Res 47: 4126-4133, 2019.

16. Martinez MEG and Domingo MVC: Size, type, and location of myoma as predictors for successful laparoscopic myomectomy: A tertiary government hospital experience. Gynecol Minim Invasive Ther 7: 61-65, 2018.

17. Koh MB and Hunt BJ: The management of perioperative bleeding. Blood Rev 17: 179-185, 2003.

18. Wise LA and Laughlin-Tommaso SK: Uterine leiomyomata. In: Women and Health. Goldman MB, Troisi R and Rexrode KM (eds). Academic Press, San Diego, pp285-306, 2013.

19. Wise LA, Palmer JR, Harlow BL, Spiegelman D, Stewart EA, Adams-Campbell LL and Rosenberg L: Reproductive factors, hormonal contraception and risk of uterine leiomyomata in African-American women: A prospective study. Am J Epidemiol 159: 113-123, 2004.

20. Wise LA, Ruiz-Narvaez EA, Palmer JR, Cozier YC, Tandon A, Patterson N, Radin RG, Rosenberg L and Reich D: African ancestry and genetic risk for uterine leiomyomata. Am J Epidemiol 176: 1159-1168, 2012.

21. Jacoby VL, Fujimoto VY, Giudice LC, Kupperman M and Washington AE: Racial and ethnic disparities in benign gynecologic conditions and associated surgeries. Am J Obsets Gynecol 202: 514-521, 2010.

22. Zimmermann A, Bernuit D, Gerlinger C, Schaefers M and Geppert K: Prevalence, symptoms and management of uterine fibroids: An international internet-based survey of 21,746 women. BMC Womens Health 12: 6, 2012.

23. Laughlin SK, Baird DD, Savitz DA, Herring AH and Hartmann KE: Prevalence of uterine leiomyomas in the first trimester of pregnancy: An ultrasound screening study. Obstet Gynecol 113: 630-635, 2019.

24. Marino JL, Eskenazi B, Warner M, Samuels S, Vercellini P, Gavoni N and Olive D: Uterine leiomyoma and menstrual cycle characteristics in a population-based cohort study. Hum Reprod 19: 2350-2355, 2004. 
25. Chiaffarino F, Cipriani S, Ricci E, La Vecchia C, Chiantera V, Bulfoni A and Parazzini F: Alcohol consumption and risk of uterine myoma: A systematic review and meta analysis. PLoS One 12: e0188355, 2017.

26. Signorell A, Aho K, Alfons A, Anderegg N, Aragon T, Arachchige C, Arppe A, Beddeley A, Barton K, et al: Desc Tools: Tools for Descriptive Statistics. R package version 0.99.40. README NEWS. 2020. https://cran.r-project.org/web/packages/DescTools/DescTools.pdf. Accessed September 8, 2021.

27. Baskett TF: 'Hysterectomy: Evolution and trends,' Best Pract Res Clin Obstet Gynaecol 19: 295-305, 2005.

28. Tinelli A, Kosmas I, Mynbaev OA, Favilli A, Gimbrizis G, Sparic R, Pellegrino M and Malvasi A: Submucous fibroids, fertility, and possible correlation to pseudocapsule thickness in reproductive surgery. Biomed Res Int 2804830, 2018.

29. Somigliana E, Vercellini P, Daguati R, Pasin R, De Giorgi O and Crosignani PG: Fibroids and female reproduction: A critical analysis of the evidence. Hum Reprod Update 13: 465-476, 2007.

30. Cramer SF and Patel A: The frequency of uterine leiomyomas. Am J Clin Pathol 94: 435-438, 1990.

31. Whiteman MK, Kuklina E, Jamieson DJ, Hillis SD and Marchbanks PA: Inpatient hospitalization for gynecologic disorders in the United States. Am J Obstet Gynecol 202: 541.e1-6, 2010.

32. Pritts EA, Parker WH and Olive DL: Fibroids and infertility: An updated systematic review of the evidence. Fertil Steril 91: $1215-1223,2009$

33. Zhang Y and Hua KQ: Patients' age, myoma size, myoma location, and interval between myomectomy and pregnancy may influence the pregnancy rate and live birth rate after myomectomy. J Laparoendosc Adv Surg Tech A 24: 95-99, 2014.

34. Husslein H, Frecker H, Shore EM, Lefebvre G, Latta E, Montanari E and Satkunaratnam A: Comparing two uterine manipulators during total laparoscopic hysterectomy: A randomized controlled trial. J Minim Invasive Gynecol 24: 764-771, 2017.

35. Hosny TA: Oophoropexy for ovarian torsion: A new easier technique. Gynecol Surg 14: 7-10, 2017.

36. Zeleniuk BI, Adamian LV, Obel'chak IS and Khoroshun ND: Role of multislice spiral computed tomographic angiography in the treatment of uterine myoma. Vestn Rentgenol Radiol 3: 34-37, 2012 (In Russian).
37. Cardozo ER, Clark AD, Banks NK, Henne MB, Stegmann BJ and Segars JH: The estimated annual cost of uterine leiomyomata in the United States. Am J Obstet Gynecol 206: 211.e1-9, 2012.

38. Mazzon I, Favilli A, Grasso M, Horvath S, Di Renzo GC and Gerli S: Is cold loop hysteroscopic myomectomy a safe and effective technique for the treatment of submucous myomas with intramural development? A series of 1434 surgical procedures. J Minim Invasive Gynecol 22: 792-798, 2015.

39. Tinelli A, Malvasi A, Mynbaev OA, Barbera A, Perrone E, Guido M, Kosmas I and Stark M: The surgical outcome of intracapsular cesarean myomectomy. A match control study. J Matern Fetal Neonatal Med 27: 66-71, 2014.

40. Stewart EA: Clinical practice: Uterine fibroids. N Engl J Med 372: 1646-1655, 2015.

41. Ertunc D, Uzun R, Tok EC, Doruk A and Dilek S: The effect of myoma uteri and myomectomy on sexual function. J Sex Med 6: 1032-1038, 2009.

42. Dilek S, Ertunc D, Tok EC, Cimen R and Doruk A: The effect of myomectomy on health-related quality of life of women with myoma uteri. J Obstet Gynaecol Res 36: 364-369, 2010.

43. Mukhopadhaya N, De Silva C and Manyonda IT: Conventional myomectomy. Best Pract Res Clin Obstet Gynaecol 22: 677-705, 2008.

44. Radosa JC, Meyberg-Solomayer G, Kastl C, Radosa CG, Mavrova R, Graber S, Baum S and Radosa MP: Influences of different hysterectomy techniques on patients' postoperative sexual function and quality of life. J Sex Med 11: 2342-2350, 2014.

45. Radosa JC, Radosa CG, Mavrova R, Wagenpfeil S, Hamza A, Joukhadar R, Baum S, Karsten M, Juhasz-Boess I, Solomayer EF and Radosa MP: Postoperative quality of life and sexual function in premenopausal women undergoing laparoscopic myomectomy for symptomatic fibroids: A prospective observational cohort study. PLoS One 11: e0166659, 2016. International (CC BY-NC-ND 4.0) License. 